\title{
Consumers' distrust about E-numbers: a qualitative study among food experts
}

\author{
Annelies Van Gunst and Annet JC Roodenburg \\ HAS University of Applied Sciences, Den Bosch, Netherlands
}

Introduction: Consumers demand healthy food products. While E-numbers are allowed in these products, many consumers have a negative perception. Food companies act on this and communicate on their package about removing E-numbers from their products or using less 'chemical-sounding' terms (clean label). Consequently, the question among food experts is how to deal with this perception and the real effects on health.

The objective was to study the opinion of food experts about the causes and ways to reduce consumers' distrust about E-numbers.

Methods: Thirteen food experts from universities, research institutes, Ministry of Health, Welfare and Sport, food industry organizations, media, The Netherlands Nutrition Centre, Dutch Consumers' Association and two other non-governmental organizations (NGOs) were interviewed with a semi-structured topic list, based on a model of risk perception. Interviews were transcribed, coded by an open coding approach and analyzed.

Results \& discussion: Results indicated that, according to food experts, this distrust of consumers arose from negative communication in the past and nowadays by the (social) media and in books. In this communication, the information source and the reliability of E-number information are important for consumers, according to food experts. Food experts suggested to reduce the distrust by avoiding negative claims on the label such as no/ reduced E-numbers, and to make collective appointments with all parties about a honest and transparent communication to consumers. Food companies need to explain clear and honest why they use E-numbers in food. The Netherlands Nutrition Centre and the Ministry of Health, Welfare and Sport were often mentioned as parties to undertake action, consumers had no confidence in the food industry, according to the experts.

\section{Conflict of Interest}

There is no conflict of interest 